University of Nebraska - Lincoln

DigitalCommons@University of Nebraska - Lincoln

Captive Supplies and the Spot Market Price of Fed Cattle: The Plant-Level Relationship

John R. Schroeter

lowa State University, johns@iastate.edu

Azzeddine Azzam

University of Nebraska-Lincoln, Aazzam1@unl.edu

Follow this and additional works at: https://digitalcommons.unl.edu/ageconfacpub

Part of the Agricultural and Resource Economics Commons

Schroeter, John R. and Azzam, Azzeddine, "Captive Supplies and the Spot Market Price of Fed Cattle: The Plant-Level Relationship" (2003). Faculty Publications: Agricultural Economics. 104.

https://digitalcommons.unl.edu/ageconfacpub/104

This Article is brought to you for free and open access by the Agricultural Economics Department at DigitalCommons@University of Nebraska - Lincoln. It has been accepted for inclusion in Faculty Publications: Agricultural Economics by an authorized administrator of DigitalCommons@University of Nebraska - Lincoln. 


\title{
Captive Supplies and the Spot Market Price of Fed Cattle: The Plant-Level Relationship
}

\author{
John R. Schroeter \\ Department of Economics, Iowa State University, 260 Heady Hall, \\ Ames, Iowa 50011-1070. E-mail: johns@iastate.edu
}

\begin{abstract}
Azzeddine Azzam
Department of Agricultural Economics, University of Nebraska-Lincoln, Lincoln, Nebraska. E-mail: aazzam@unlnotes.unl.edu
\end{abstract}

\begin{abstract}
Numerous articles in the agricultural economics literature investigate the empirical relationship between the spot market price of fed cattle and the volume of packers' precommitted, or "captive," supplies of cattle. In this article, we use an extensive data set on the cattle procurement activities of four large packing plants in the Texas Panhandle from early 1995 through mid-1996 to examine this relationship at the plant-level. We find evidence to support the hypothesis that plants that anticipate near-term future deliveries of captive supply cattle that are high relative to their regional-market rivals' degrees of reliance on captive supplies tend to pay spot market prices that are below average. The effect, while statistically significant, is relatively small in magnitude, however.
\end{abstract}

\section{Introduction}

Beef packing plants use a variety of means of procuring fed cattle for slaughter. The traditional method, which still accounts for the majority of fed cattle marketed, is the "cash" or "spot" market purchase in which a buyer inspects cattle at the feed-yard, and submits lot-specific price bids, usually on a live-weight basis. Cattle procured by this means are normally shipped to the plant within about 1 week of purchase. Other procurement methods commit the cattle to the buyer for longer periods of time. These methods, commonly known as "captive supply" procurement methods, include marketing agreements, forward contract sales, and packer-feeding of cattle. In 1999, 23.6\% of steer and heifer slaughter by the 15 largest packers represented captive supply cattle (Grain Inspection, Packers and Stockyards Administration, 2002). The effect of captive supplies on the spot market for fed cattle is a topic of considerable policy debate and has been the subject of numerous articles in the agricultural economics literature and two recent investigations sponsored by the Grain Inspection, Packers and Stockyards Administration (GIPSA) 
of the USDA. ${ }^{1}$ Several of these studies involve the use of data in an effort to characterize the empirical relationship between captive supply usage and spot market price. What has sometimes been lacking in this work is explicit recognition of the fact that there actually are at least two kinds of captive-supply-cash-price relationships that are very different in their empirical manifestations, their economic causes, and their policy relevance.

Much of the interest in captive supplies stems from the perception that their use somehow leads to lower prices, on average, for cattle in the spot market, and therefore, is harmful to cash market sellers of fed cattle. The relationship that is most relevant to this hypothesis is the one between the volume of captive supply deliveries in a region, on the one hand, and the regional market's average quality-adjusted spot price for fed cattle, on the other. Several authors, using a variety of data sets and empirical techniques, have investigated this "market-level" relationship. Generally speaking, they have found that fed cattle prices in a regional cash market tend to be low on average in periods in which the region's captive supply delivery volume is high. ${ }^{2}$ In other work (Schroeter \& Azzam, 1999, 2002), we provide additional evidence of this empirical regularity and address its relevance for policy making.

Once again, the market-level relationship is concerned with the pattern of covariation, over time, between a regional market's aggregate volume of captive supply deliveries and the average price of fed cattle in the cash market. The focus of the present article, however, is another kind of captive-supply-cash-price relationship: the relationship across packing plants, at a given point in time, between the degree of reliance on captive supply sources and the quality-adjusted spot market prices paid relative to the market's current average price. When a plant's use of captive supplies is high, does it tend to pay spot prices that are toward the low end of the market's distribution of prices? Intuition suggests that it does. A packer with a relatively large share of planned slaughter volume already committed in the form of scheduled captive supply deliveries would want to supplement those cattle with relatively few cash market purchases. Thus, freed from the necessity of aggressive bidding on the cash market, the packer should be able to make cash market purchases at quality-adjusted prices that are low relative to average. ${ }^{3}$ In this article, we formalize that argument slightly and provide some empirical evidence to support it and to gauge the magnitude of the effect.

The next section briefly reviews some of the institutional features of fed cattle markets that are pertinent to the analysis. Section 3 presents a simple graphical model that predicts a plant-level relationship of the kind described in the previous paragraph. In Section

\footnotetext{
${ }^{1}$ Papers dealing with this topic include; Azzam (1998); Elam (1992); Hayenga and O'Brien (1992); Love and Burton (1999); Schroeder, Jones, Mintert, and Barkley (1993); Schroeter and Azzam (2002); Ward, Koontz, and Schroeder (1998); Ward, Koontz, Dowty, Trapp, \& Peel (1999); and Zhang and Sexton (2000). The two GIPSAsponsored studies are reported in Ward, Koontz, and Schroeder (1996); and Schroeter and Azzam (1999). Widespread interest in the topic prompted the USDA to sponsor a Public Forum on Captive Supplies in the Livestock Industry in Denver, CO, on September 21, 2000.

${ }^{2}$ Empirical investigations finding at least some evidence of an inverse relationship between captive deliveries and cash prices at the market level include Elam (1992), Hayenga and O'Brien (1992), and Schroeder et al. (1993).

${ }^{3}$ Both Ward et al. (1998) and Schroeder et al. (1993) report the results of regressions that are pertinent to the plant-level relationship insofar as they explain the price paid for a lot of spot market cattle in terms of some measure of captive supply usage by the purchasing plant. Schroeter and Azzam (1999) also carry out an empirical investigation of the plant-level relationship. This article presents a revised version of the analysis undertaken in section VIII.2 of that report.
} 
4, the hypothesis is tested empirically. Section 5 interprets the results and discusses their relevance to the captive supply policy debate. Briefly, although our investigation uncovers an inverse relationship in one specific type of captive-supply-cash-price comparison, we argue that it should not be used as a justification for policies designed to restrict the use of captive supplies. A concluding Section 6 provides a summary.

\section{Institutional Considerations}

As part of a recent investigation of the effects of captive supplies, GIPSA collected data on the cattle procurement activities of four large beef-packing plants in the Texas Panhandle over the period from early February 1995 through mid-May 1996. Additional detail about the information collected in the GIPSA investigation is provided in Schroeter and Azzam (1999). The inquiry solicited information on every lot of cattle, of over 35 head, purchased by the four plants during the period of study. The investigation also conducted interviews with feedyard managers and packing company personnel about various aspects of cattle markets. The records of the plants' cattle procurement activities are the source of the data used in this article and some of the features of the market that were revealed in interviews are reflected in our modeling assumptions.

Captive supply procurement methods include marketing agreements, forward contract sales, and packer-feeding of cattle. Marketing agreements are formal or informal standing arrangements between a packer and a feeder for the delivery of cattle on an ongoing basis. These agreements include the stipulation that the cattle will be priced according to a formula consisting of a base price, that is tied to current spot market prices, and a system of premia and discounts used to adjust the base price for variation in the quality of delivered cattle. Unlike marketing agreements, forward contract sales involve explicit contracts for delivery of a specified number of cattle in a particular future month. Most of these take the form of basis forward contracts in which the buyer bids a futures market basis for the delivery month. "Packer-fed" cattle are owned by the packer during the feeding process, which usually takes place in independently owned feedlots with which the packer has contracted for feeding services.

In the case of marketing agreement cattle, the feeder determines the number of cattle to be delivered to a plant under a given marketing agreement within a given week. More importantly for our analysis, GIPSA interview reports suggest that the delivery volume for a particular week is normally determined and reported to the packer 2 weeks in advance. ${ }^{4}$

The terms of conventional forward contracts reserve for the buyer the right to specify the day of delivery within the delivery month. Anecdotal evidence suggests, however, that delivery timing is usually a mutual decision between the buyer and the feedlot, with an effort made to deliver cattle when their optimal potential is reached. Once the decision to deliver is made, there can be a time lag attributable to delays in arranging for transportation. The data from the Texas Panhandle investigation suggest that the number of for-

\footnotetext{
${ }^{4}$ In making the judgment that the volume of marketing agreement deliveries is normally determined 2 weeks in advance of delivery, we are relying on our interpretation of the interview reports summarized in Appendix B of Schroeter and Azzam (1999). The transaction data from the Texas Panhandle investigation do not contain information about the date on which the feeder notified the packer of the number of cattle to be delivered during a given week.
} 


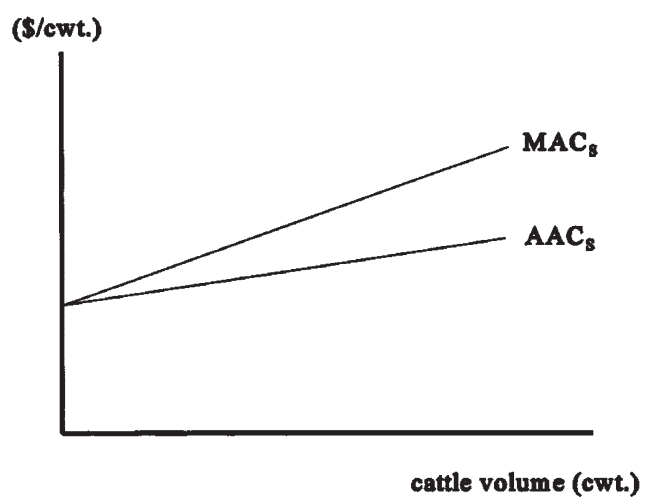

Figure 1. Average and Marginal Acquisition Cost of Spot Market Cattle

ward contract cattle to be delivered in a given week is normally decided 1 to 2 weeks in advance. $^{5}$

Packer-fed cattle made a relatively insignificant contribution to total slaughter numbers for the four Texas plants during the period of investigation. ${ }^{6}$ Obviously, the packer has complete discretion over when to utilize packer-owned supplies of cattle. As with other captive supply sources, however, delays in arranging transportation mean that a week's delivery volume of packer-fed cattle would normally be determined at least a few days in advance.

\section{The Plant-Level Behavioral Model}

For our purposes, the main implication of the institutional details reviewed in the previous section is that a packer, upon entering the spot market with the intention of purchasing cattle for slaughter over a given period of time; a given week, say; typically knows the volume of captive supply deliveries already scheduled for that week. For any given packer, moreover, this volume of precommitted supplies tends to vary from week to week. The following graphical model shows how the packer's spot market cattle purchases and average spot market price is likely to vary in response to week-to-week fluctuations in the volume of captive supply deliveries.

Figure 1 depicts the residual supply curve of spot market cattle facing an individual packer. Labeled AACS, for average acquisition cost of spot market cattle, this curve represents the regional spot market's overall supply net of spot cattle demands by other packers in the region. Defined in this way, the residual supply curve consists of the locus of pricequantity combinations available to the packer in its spot market dealings for the time period under consideration. The fact that the curve slopes upward reflects our assumption that the packer is not a price-taker in its regional spot cattle market: The price it must pay is not independent of the number of spot cattle it purchases. For given market conditions, purchas-

\footnotetext{
${ }^{5}$ For forward contract lots, the GIPSA data usually contain the "scheduling date," the date on which the lot's delivery date is fixed by the packer. For these lots, the distribution of the number of days from the scheduling date until the kill date has a mean of 11.88 days and a standard deviation of 7.98 days.

${ }^{6}$ For the study's four packing plants during the period of investigation, the percentages of steer and heifer slaughter attributable to each procurement method were as follows: spot market, $71.3 \%$; packer-fed, $2.5 \%$; forward contract, $5.2 \%$; marketing agreement, $21.0 \%$.
} 


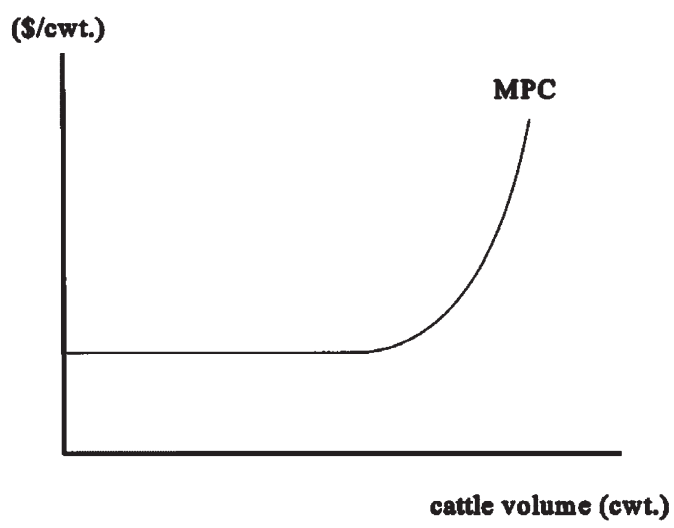

Figure 2 Marginal Processing Cost

ing a greater number of cattle requires that the packer bid more aggressively causing the average spot cattle acquisition cost to rise, at least slightly. ${ }^{7}$ Of course, the position of the packer's residual supply curve can shift with shifts in regional supply or with changes in rival packers' spot marketing conduct for the period. Because residual supply, representing average cattle acquisition cost, is upward sloping, marginal cattle acquisition cost, also depicted in Figure 1 and labeled MACS , lies everywhere above it.

Figure 2 depicts the packer's marginal slaughter/processing cost for cattle, labeled MPC, and drawn so as to indicate an approximately constant marginal processing cost out to plant "capacity" at which point marginal cost rises sharply. Figure 3 depicts the output demand curve, or average revenue curve (labeled AR), that the packer faces. As drawn here, with a slight downward slope, the packer is assumed to possess some influence over price in the output market as well: if the packer were to sell more output, it would drive the price down slightly. If, instead, the packer's output price were independent of its sales, demand would be horizontal. Marginal revenue, denoted MR in Figure 3 , lies everywhere below demand. ${ }^{8}$

Now consider a packer with a given volume of captive supply deliveries already committed for the decision period. The acquisition cost of these cattle is sunk and so will not affect the packer's spot market purchase decision. ${ }^{9}$ The packer's relevant marginal cost curve, therefore, is MPC alone, out to the precommitted captive supply delivery volume,

${ }^{7}$ A number of empirical studies have found evidence that packers have at least some influence on price in their cattle input markets. For example, see Schroeter (1988). Again, this simply means that a typical individual packer perceives an upward sloping relationship between the number of spot market cattle procured, in any given time period, and the average acquisition cost of these cattle. We do not suggest that this influence on price is attributable, in any sense, to the use of captive supply procurement methods.

8 The model's conclusions require that $\mathrm{AAC}_{\mathrm{s}}$ and $\mathrm{MAC}_{\mathrm{s}}$ slope upward, and at least one of the following: MR slopes downward or MPC slopes upward at the equilibrium point.

${ }^{9}$ Our model's assumption of a sunk cost of captive supply cattle raises one detail that requires further attention. In the case of formula-priced, marketing agreement cattle, the price to be paid for cattle delivered next week depends on a base price, which in turn, is derived from spot market prices this week. In some cases, the formula's base price is derived from a USDA reported market price, leaving little or no opportunity for an individual packer to manipulate the formula base. In other cases, however, the base price is tied to the prices of the packer's own spot market purchases. This raises the possibility that a packer, when expecting delivery of unusually large numbers of marketing agreement cattle, might pay low quality-adjusted prices on the spot market so as to reduce the formula base and, therefore, the cost of the upcoming marketing agreement deliveries. To investigate this possibility empirically, one must distinguish between the two kinds of pricing formulas: 


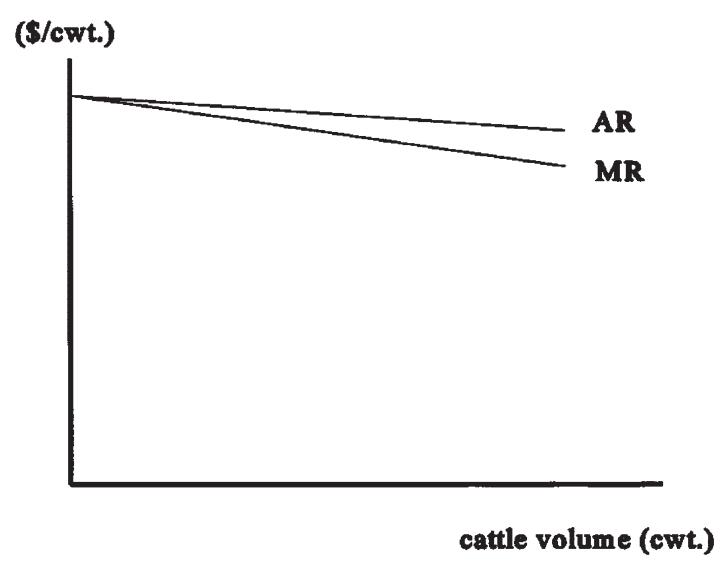

Figure 3. Average and Marginal Revenue

and is given by the vertical sum of MPC and MACS beyond that point. Figure 4 shows two such marginal cost curves, $\mathrm{MC}_{1}$ and $\mathrm{MC}_{2}$, corresponding to precommitted captive supply volumes $\mathrm{CS}_{1}$ and $\mathrm{CS}_{2}$, respectively. In either case, the packer will purchase spot market cattle in numbers sufficient to bring total slaughter volume to the profit maximizing point at which $\mathrm{MC}=\mathrm{MR}$. With precommitted supply volume $\mathrm{CS}_{1}$, profits are maximized with total slaughter of $\mathrm{TS}_{1}$ achieved with spot market purchases of $\mathrm{TS}_{1}-\mathrm{CS}_{1}$. Alternatively, suppose that the packer entered the decision period with the larger volume of precommitted supplies, $\mathrm{CS}_{2}$, while the position of its residual spot market supply remains unchanged. Then optimal total slaughter would be $\mathrm{TS}_{2}$, achieved with spot market purchases of $\mathrm{TS}_{2}-\mathrm{CS}_{2}$. Because $\mathrm{TS}_{2}-\mathrm{CS}_{2}$ is less than $\mathrm{TS}_{1}-\mathrm{CS}_{1}$, and because the packer's residual supply is upward sloping, the packer will pay a lower average price for spot market cattle with precommitted deliveries $\mathrm{CS}_{2}$ than with $\mathrm{CS}_{1}$ : for a given packer, facing a given residual supply curve of spot market cattle, higher volumes of precommitted captive supply deliveries will tend to be associated with lower prices paid on the spot market.

Notice the qualification emphasized with italics in the last sentence. Its importance can be seen by considering two simple examples. Suppose, on the one hand, that the scheduled captive supply deliveries of all packers in the region were to increase by the same factor, say $20 \%$, from 1 week to the next. The resulting drain on the number of cattle that would otherwise be available on the spot market would shift back the residual supply curves facing each packer. Thus, while each packer may well purchase fewer spot market cattle as a result of its increase in anticipated delivery numbers from captive supply sources, it is not obvious that they would be able to make those purchases at lower prices on average. Now, on the other hand, suppose that a given packer anticipates a $20 \%$ increase in captive supply deliveries over last week's figures and that this increase will be offset by a reduction in the scheduled captive supply deliveries to other packers in the regional market. In this case, one would expect little or no shift in the residual supply curve facing the packer anticipating increased captive supply deliveries. The analysis of the previous paragraph would apply, and the packer with an increase in the scheduled volume

those with base prices tied to USDA market reports and those with base prices derived from the packer's own spot market prices. We undertook this kind of investigation in Section IX of Schroeter and Azzam (1999) and found no evidence that packers try to manipulate formula base prices in this way. 


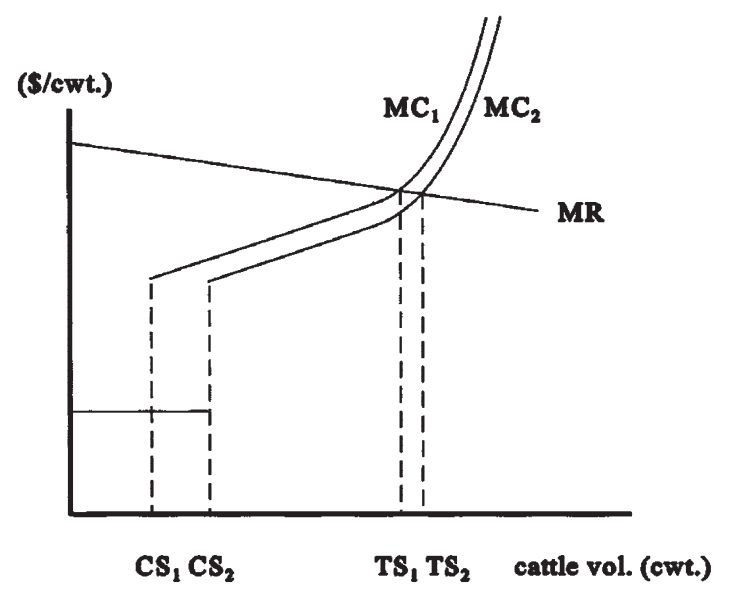

Figure 4. Profit Maximization

of captive supply deliveries would purchase fewer spot market cattle at lower average prices than the previous week.

Consideration of the two scenarios described above suggests that prices paid on the spot market are actually a function of the packer's scheduled captive supply delivery volume relative to rival packers' scheduled noncash delivery volumes. It is when a packer anticipates deliveries of captive supply cattle that are high relative to its rivals' degrees of reliance on captive supply sources for the same period that we might expect the packer to make spot market purchases at low prices. Moreover, "low prices," in this context, is also a relative concept. In any given week in any given regional spot market, there is, in fact, an entire distribution of prices paid for fed cattle; a distribution that shifts, from week to week, due to changes in market conditions. By a "low" price, we mean a price that is low relative to the mean of the price distribution representative of current market activity. These observations lead to the following hypothesis:

Packers tend to pay spot market cattle prices that are low compared to the regional market's average price when they anticipate near-term future deliveries of cattle from captive supply sources that are high, as a proportion of total slaughter volume, relative to rival packers' degrees of reliance on captive supply sources over the same period.

\section{Empirical Model and Testing}

We will undertake an investigation of this hypothesized relationship between spot market prices paid and packers' scheduled captive supply delivery volumes using a multiple regression analysis of a data set with observations corresponding to individual lots purchased on the spot market. The dependent variable, RPRICE, is the "relative price" paid for the lot, defined as the price of the lot's cattle; on an FOB feedyard, live weight basis, minus the weighted average price of steers reported by AMS for the OklahomaTexas panhandle region on the day of purchase of the lot, in \$/cwt. Defined in this way, RPRICE can be interpreted as the lot's price's departure from a representative average price for the day of purchase. 
The key explanatory variable will capture the effect on relative spot market prices of changes in the relative volume of scheduled deliveries of fed cattle from captive supply sources. To understand how this variable should be properly measured, some timing considerations must first be addressed. Again, when a packer purchases cattle on the spot market "today," it is with the intention of slaughtering those cattle over some future period, or "planning horizon."So, as argued using the graphical model of the previous section, spot prices paid today should be connected to the packer's relative degree of reliance on captive supplies over the planning horizon. Of course, there is no obviously correct choice for the beginning and ending dates of the planning horizon relevant to today's spot market pricing conduct for a given packer. Our approach to the problem is to define the planning horizon for a given packer and a given spot market purchase day in terms of the actual disposition of the spot cattle purchased on that day. In particular, we take the starting and ending dates of the planning horizon to be, respectively, the earliest kill date and the latest kill date for the lots of spot market cattle purchased by the plant today. For the four plants combined, the earliest kill date and the latest kill date for a day's spot market cattle purchases averaged 4.5 and 10.7 days after the purchase day, respectively.

The captive supply variable, which we call "relative ratio" and denote RRATIO, is then defined in terms of this planning horizon via the following construction: for each day on which spot market purchases were made, and for each packer, we first calculate the value of "RATIO," the proportion of total steer and heifer slaughter, over the planning horizon, that is attributable to captive supplies. Then, for each spot market lot purchased on that day, take the value of RRATIO to be the purchasing packer's value of RATIO expressed as a deviation from the average value of RATIO for the four Texas plants on that purchase day. For example, suppose that for a given spot market purchase day, the four plants' total fed cattle slaughter volumes over their respective planning horizons contained the following proportions of cattle from captive supply sources: $0.30,0.14,0.26$, and 0.34 for plants $\mathrm{A}, \mathrm{B}, \mathrm{C}$, and $\mathrm{D}$, respectively. Then a lot purchased by plant $\mathrm{A}$ on that day would be assigned an RRATIO value of $0.04(=0.30-(0.30+0.14+0.26+0.34) / 4) .{ }^{10}$ With RRATIO defined in this way, a high (low) value for a given lot means that the plant purchasing the lot anticipates a degree of reliance on captive supplies, over the planning horizon, that is high (low) relative to that of its rivals.

Besides RRATIO, additional explanatory variables were included in the regression to control for other sources of systematic variation in prices across plants and through time, and to account for the effects of a variety of lot quality indicators that may influence price. The definitions of these variables are provided in Table 1 . In addition to the variables defined in the table, the menu of explanatory variables also included three sets of dummy variables identifying the purchase day of the week (MON, TUE, WED, THU), the purchasing plant, and the purchase week of the sample.

The original data set recorded 24,425 spot market purchases of lots of fed cattle by the four Texas plants combined. Of these, 3,157 had to be deleted due to data problems. ${ }^{11}$

10 These are hypothetical figures, for purposes of illustration only, and do not represent actual differences among plants.

11 Two thousand three hundred forty-two lots were deleted because the FOB feedyard price, which is required to determine the value of the model's dependent variable, was not recorded. Three lots were dropped because of other missing or obviously incorrect data entries. An additional 812 were deleted because the recorded entry for the lot's total delivered cost (which should include transport cost) was less than or equal to the entry for FOB feedyard cost (which should exclude transport cost). Although this inconsistency does not necessarily mean that the value for FOB feedyard price (FOB feedyard cost divided by the lot's total live weight) is in error, it at least casts some suspicion on its accuracy. 
Table 1. Definitions of the Independent Variables Used in the Fed Cattle Relative Price Model

\begin{tabular}{|c|c|}
\hline Variable Name & Definition (Units of Measurement) \\
\hline HEAD & number of cattle in the lot (head). \\
\hline YIELD & the lot's total hot weight divided by total live weight (\%). \\
\hline РCTPC & percentage of lot graded Prime or Choice (\%). \\
\hline PCTYG13 & percentage of lot achieving yield grades of 1,2 , or $3(\%)$. \\
\hline MILES & the distance the cattle were shipped to the plant (miles). \\
\hline MILES2 & the square of the distance the cattle were shipped to the plant (miles2). \\
\hline HEIFER & $\begin{array}{l}\text { a dummy variable equal to } 1 \text { if the lot consists of heifers, and equal to } 0 \\
\text { otherwise. }\end{array}$ \\
\hline MIXED & $\begin{array}{l}\text { a dummy variable equal to } 1 \text { if the lot consists of a mixture of steers and heifers } \\
\text { and equal to } 0 \text { otherwise. }\end{array}$ \\
\hline AWS & $\begin{array}{l}\text { the lot's average carcass weight, if the lot consists of steers; equal to } 0 \text { otherwise } \\
\text { (lb.). }\end{array}$ \\
\hline AW2S & $\begin{array}{l}\text { the square of the lot's average carcass weight, if the lot consists of steers; equal to } \\
0 \text { otherwise }\left(\mathrm{lb}^{2}\right) \text {. }\end{array}$ \\
\hline AWH & $\begin{array}{l}\text { the lot's average carcass weight, if the lot consists of heifers; equal to } 0 \text { otherwise } \\
\text { (lb.). }\end{array}$ \\
\hline $\mathrm{AW} 2 \mathrm{H}$ & $\begin{array}{l}\text { the square of the lot's average carcass weight, if the lot consists of heifers; equal } \\
\text { to } 0 \text { otherwise }\left(\mathrm{lb}^{2}\right) \text {. }\end{array}$ \\
\hline AWM & $\begin{array}{l}\text { the lot's average carcass weight, if the lot consists of a mixture of steers and } \\
\text { heifers; equal to } 0 \text { otherwise (lb.). }\end{array}$ \\
\hline AW2M & $\begin{array}{l}\text { the square of the lot's average carcass weight, if the lot consists of a mixture of } \\
\text { steers and heifers; equal to } 0 \text { otherwise }\left(1 \mathrm{~b} .^{2}\right) \text {. }\end{array}$ \\
\hline
\end{tabular}

Eight lots were dropped because they were priced on a carcass-weight basis instead of a live-weight basis; an indication that there may have been something unusual about these lots. To be usable in the analysis, lots had to have been purchased on days for which an AMS report of steer prices was available. As a practical matter, this restricted the sample to lots purchased on week days. Also, because the planning horizon is forward-looking, the sample does not contain information sufficient for the calculation of the value of RRATIO on some of the purchase days toward the end of the sample period: Lots purchased during the sample's last 2 weeks were dropped. These last two requirements led to the elimination of another 814 lots, bringing the usable total down to 20,446. Finally, the manner in which RRATIO is defined requires that attention be limited to the lots purchased on days on which all four plants registered spot market purchases. The sample period that remained after the last 2 weeks were dropped consisted of 65 weeks or 325 week days. The numbers of days of spot market activity averaged about 219 across the four plants, but there were only 148 days in the sample on which all four plants purchased on the spot market. Restricting attention to lots purchased on just these 148 days brings the sample to a final size of 17,846 observations.

The model was estimated by ordinary least squares. Results are reported in Table 2. The regression's $R^{2}$ value of 0.2037 indicates that just over $20 \%$ of the variation in the model's dependent variable is explainable in terms of the regressors. Although this proportion may seem low, it should be borne in mind that the dependent variable is defined as the price of each sample lot's cattle expressed as a departure from the region's average cattle price for the day of purchase. Thus, a considerable portion of the variation in lot prices is already removed; this regression seeks to explain the residual variation. Col- 
Table 2. Ordinary Least Squares Estimates of the Fed Cattle Relative Price Model.

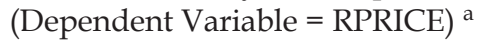

\begin{tabular}{lccr}
\hline Parameter & $\begin{array}{c}\text { Standard } \\
\text { Independent Variables }\end{array}{ }^{b}$ & t-Statistic for $\mathrm{H}_{0}:$ & \\
Estimate & Error & Parameter $=0$ \\
\hline INTERCEPT & -24.042 & 1.189 & -20.23 \\
RRATIO & -0.2122 & 0.0633 & -3.35 \\
HEAD & 0.00033 & 0.000038 & 8.59 \\
YIELD & 0.12192 & 0.00509 & 23.94 \\
PCTPC & 0.00018 & 0.00031 & 0.58 \\
PCTYG13 & 0.01739 & 0.00096 & 18.05 \\
MILES & -0.00085 & 0.00017 & -4.98 \\
MILES2 & -0.0000049 & 0.00000048 & -10.32 \\
HEIFER & -9.0546 & 1.7969 & -5.04 \\
MIXED & 3.7906 & 3.8071 & 1.00 \\
AWS & 0.03892 & 0.00302 & 12.88 \\
AW2S & -0.000026 & 0.000002 & -12.96 \\
AWH & 0.07158 & 0.00401 & 17.85 \\
AW2H & -0.000054 & 0.000003 & -18.87 \\
AWM & 0.03047 & 0.01001 & 3.04 \\
AW2M & -0.000022 & 0.000007 & -3.18 \\
MON & 0.00596 & 0.03797 & 0.16 \\
TUE & 0.00672 & 0.02867 & 0.23 \\
WED & -0.03743 & 0.02690 & -1.39 \\
THU & -0.03611 & 0.02808 & -1.29 \\
\hline
\end{tabular}

$R^{2}=0.2037 ; R^{2}=0.2000$. Number of observations $=17,846 ;$ F-value $=55.40$.

a The dependent variable, RPRICE, is the price of cattle in the lot, FOB feedyard, on a live weight basis, minus the weighted average steer price, as reported by AMS, for the day of purchase of the lot, in $\$ /$ cwt.

${ }^{\mathrm{b}}$ The key independent variable is RRATIO+ For a given lot, RRATIO is defined as the captive supply proportion of the purchasing plant's steer and heifer slaughter over the planning horizon, expressed as a deviation from the four plants' current average of these proportions. Most of the other independent variables are defined in Table 1. In addition to the variables in Table 1, the model includes a set of dummy variables for the purchaseday-of-the-week (MON, TUE, WED, and THU), dummy variables identifying three of the four plants in the sample, and a set of purchase week dummy variables for 60 of the 61 weeks represented in the sample. Estimates of the coefficients of the purchase week dummy variables are omitted to save space. Estimates of the plant dummy coefficients are withheld because of disclosure restrictions.

lectively, the explanatory variables contribute significantly to the explanation of the variation in the dependent variable: The $F$-value of 55.40 enables a rejection, at a marginal significance level that is virtually zero, of the hypothesis that all parameters (other than the intercept term) are zero.

We undertook tests of the joint significance of certain sets of explanatory variables. Our approach of expressing the dependent variable as a deviation from the AMS reported average steer price for the purchase day is one way to control for variation in broad market price influences. With this method of control built into the model, it is natural to ask whether the purchase week dummy variables (whose coefficient estimates are not reported in Table 2) contribute any additional explanatory power. In fact, about $40 \%$ of the purchase week dummy coefficients were individually significant at the $5 \%$ level, with values ranging from $-\$ 0.36 / \mathrm{cwt}$. to $+\$ 0.57 / \mathrm{cwt}$., and the hypothesis that all purchase week dummies can be excluded is rejected with a marginal significance level of well below $0.01 \%$. When the model was estimated without the purchase week dummies, the $R^{2}$ 
was reduced to 0.1868 , but there was very little impact on the estimates of the coefficients of the other variables.

Another set of explanatory variables (YIELD, PCTPC, PCTYG13, HEIFER, MIXED, AWS, AW2S, AWH, AW2H, AWM, and AW2M) summarizes the quality of cattle in the lot. Estimation of the model with these variables omitted reduces $R^{2}$ drastically to 0.1000 ; their exclusion can be rejected with a marginal significance level that is essentially zero. The individual estimates of the coefficients of these quality variables were generally consistent with expectations based on intuition and secondary information. Although this provides an important validation of the model's performance, we choose, for the sake of brevity, to relegate a detailed discussion of these results to the Appendix.

Primary interest focuses on the results with respect to the variable RRATIO. The null hypothesis that the coefficient of RRATIO is zero can be rejected in favor of the one-sided alternative that it is negative at the $0.1 \%$ significance level. This finding is statistical evidence in support of our hypothesis: When packers anticipate near-term future deliveries of captive supply cattle that are large relative to total fed cattle slaughter volume, and relative to their rivals' degrees of reliance on captive supplies for the same period, they tend to pay spot market prices that are low relative to the market's current average price. We can base an estimate of the magnitude of the effect on the parameter estimate reported in Table 2. Over the entire sample period, the proportion of the four plants' combined fed cattle slaughter that was attributable to captive supplies was approximately 0.29 . Imagine that, from 1 week to the next, a plant experiences an increase in its near-term future captive supply proportion from 0.29 to 0.39 while, at the same time, there are offsetting changes in the use of captive supplies by the other plants. In this case, the plant's value of RRATIO would increase by 0.1 . The parameter estimates suggest that the effects of this change would be a decrease, relative to the market's average price, of $0.021 \$ / \mathrm{cwt}$ in the quality-adjusted spot prices paid by the plant. This figure compares to the sample-wide average spot price of $64.56 \mathrm{\$} / \mathrm{cwt}$. Thus, the effect, though highly statistically significant, is quite small in magnitude. ${ }^{12}$

\section{Interpretation of Results}

To interpret the results of the empirical analysis in the previous section, one must first distinguish between "price discovery" and "price determination." Following Ward and Schroeder (1997):

Price determination is the interaction of the broad forces of supply and demand which determine the market price level...Price discovery is the process of buyers and sellers arriving at a transaction price for a given quality and quantity of a product at a given time and place,... (and) begins with the market price level. Because buyers and sellers discover prices on the basis of uncertain expectations, transaction prices fluctuate around that market price level.

12 We believe that our method for defining the planning horizon underlying the definition of RRATIO is a reasonable approach, but it is not the only approach. As a check on the robustness of our results, we replicated the analysis with RRATIO defined in terms of two alternative planning horizons relevant to today's spot market purchases: the period of 7 days following today and the period of 14 days following today. In each of these alternative specifications, results for the coefficient of RRATIO were qualitatively similar to those reported in Table 2.The point estimates were -0.4115 and -0.2182 ,for the 7 -day and 14-day horizons, respectively, with marginal significance levels (for one-tailed tests) of less than $0.5 \%$ in each case. Results for the coefficients of the other explanatory variables were also very similar to those reported in Table 2. 
Consistent with this view, the price of fed cattle in any one regional market at any given date is characterized, not by a single point value, but by a distribution of values. The general location of the distribution, represented by its mean, is determined, in Ward and Schroeder's words, "by the broad forces of supply and demand." But transaction prices on individual lots of cattle can depart from the regional average price for a variety of reasons.

First of all, individual lots of cattle can be priced above or below the market average price because of better or worse than average lot quality. This, of course, was the motivation for including several lot quality indicators among the explanatory variables in the price regression. Also, as is discussed in the appendix, the estimation results for the coefficients of these quality indicators are generally consistent with the common-sense expectations that higher than average quality lots are rewarded with a premium and lower than average quality lots suffer a discount, relative to the regional average price.

Transaction prices may differ, however, even across lots of cattle of given quality. On any given market day, competitive conditions may vary within the regional market. A feedyard in one part of the region may be visited by only one bidder and, consequently, receive relatively low bids. For feedyards, in other parts of the region, competition among two or three bidders may be the norm for that day, and bids may be higher as a result.

A packer enters the spot market intending to procure fed cattle for slaughter for a given planning horizon. The volume of deliveries of cattle from captive supply sources that the packer will receive over that horizon is known in advance. As the graphical model of Section 3 shows, a packer who enters the spot market expecting a relatively large volume of captive supply cattle to be delivered during the planning horizon, will seek to supplement these precommitted supplies with relatively few spot market purchases. As long as the packer possesses some degree of influence over price in the spot market (that is; as long as the packer faces a spot market residual supply curve that is upward sloping), buying fewer spot market cattle will mean paying lower spot market prices, on average. On the other hand, a packer who enters the spot market expecting relatively few deliveries from captive supply sources in the near-term future, will seek to make relatively many spot market purchases. To do so, more aggressive bidding will be needed and average transaction prices will be correspondingly higher.

Consequently, one would expect that packers who enter the spot market with a "high" value of Section 4's RRATIO variable will, other things being equal, pay prices below the mean of the transaction price distribution. Packers who have a "low" value for RRATIO will tend to procure cattle at prices above the mean of the distribution. This is the phenomenon reflected in the statistically significantly negative estimate of the coefficient of RRATIO. As noted, however, the magnitude of this effect appears to be relatively small.

As we mentioned in the Introduction, there is an on-going captive supply policy debate fueled by the belief that the use of captive supplies leads to lower cash market prices and, therefore, is harmful to cash market sellers. It is sometimes suggested that packers' use of captive supplies is a strategy specifically designed to depress cash prices. We emphasize that we do not interpret our results as lending support to either of those views. Proper interpretation of the coefficient of RRATIO requires attention to details of model specification. Recall that our menu of explanatory variables includes plant-specific dummy variables. Because of this, the coefficient of RRATIO reflects only the effects of short-term fluctuations in the relative captive supply proportion about plant-specific average values, rather than any effects of systematic differences in these 
average values. ${ }^{13}$ Within our final sample of 148 days of spot market activity, each of the four plants exhibited both positive and negative values for RRATIO; that is, each operated under conditions of both higher than average and lower than average captive supply delivery commitments. But the overall sample average captive supply proportions of total slaughter differed significantly across the four plants. Any price effects attributable to these differences are not reflected in the coefficient of RRATIO but, instead, contribute to differences in the plant-specific intercept terms. To that extent, however, they are confounded with the effects of all other not-otherwise-accounted-for plant-specific characteristics.

It is also clear that the coefficient of RRATIO is not indicative of any impact on cash prices of an across-the-board change in plants' propensities to use captive supplies. This is easily seen by noting that RRATIO measures a packer's degree of reliance on captive supplies relative to its rivals' degrees of reliance on captive supplies: An across-the-board change in the average level of noncash purchases would leave RRATIO unaffected.

Thus, the relevance of the RRATIO coefficient is limited to the relative price effects of short-run departures from the mean of a plant's relative degree of captive supply reliance. The final point to be made in this connection is that the plant's control over this short-run variation in RRATIO might be quite limited. First of all, a given plant's RRATIO value for a given day is defined relative to its rivals' current use of captive supplies and therefore depends, in part, on its rivals' cattle procurement practices. ${ }^{14}$ More importantly, for the case of cattle sold via marketing agreements, the noncash procurement method accounting for $73 \%$ of captive supply volume in our sample, delivery scheduling appears to be the prerogative of the feeder, not the packer. ${ }^{15}$

\section{Summary}

Several empirical studies in the agricultural economics literature have uncovered inverse relationships, of one sort or another, between captive supply use and spot prices for fed cattle. In our work, we began by first drawing a careful distinction between two kinds of captive-supply-spot-price relationships that we dubbed the "market-level" and the "plant-level" relationships. The present article addresses the plant-level relationship. Using an extensive data set on the cattle procurement activities of four large packing plants in the Texas Panhandle, we investigated the plant-level relationship and found that packers tend to pay spot market prices that are low compared to the regional market's average price when they anticipate near-term future deliveries of cattle from captive supply sources that are high relative to total slaughter volume and relative to rival packers' degrees of reliance on captive supply sources over the same period. The effect is statistically significant but relatively small in magnitude.

We argue, moreover, that this finding does not indict captive supply procurement methods as the culprit responsible for "low" cash market prices, and should not be used

${ }^{13}$ In the implementation of the estimation procedure, the values of RRATIO were, in fact, normalized by subtracting the corresponding plants' sample average values of RRATIO. This normalization affects only the estimates of the plant-specific intercept terms, not the estimate of the coefficient of the RRATIO variable.

${ }^{14}$ For each of the four plants, the values for RRATIO and for RATIO (the plant's own proportion of captive supply cattle over the planning horizon) were positively correlated, however.

${ }^{15}$ Evidence supporting this claim is presented in Appendix B of Schroeter and Azzam (1999). 
as a justification for policies that restrict the use of captive supplies. Even if there were no cattle procured via captive supply methods, there would still be a distribution of spot market transaction prices with, at any given point in time, some packers paying above average prices and some paying below average prices. Our regression results have implications only about the identities of packers who happen to buy at low-end prices and those who buy at high-end prices: Other things equal, packers that currently have a high relative degree of reliance on captive supplies tend to pay slightly lower than average prices while packers that currently have a low relative degree of reliance on captive supply procurement methods tend to pay slightly higher than average prices.

\section{Appendix. Discussion of the Results of Estimation of the Relative Price Model}

This appendix discusses the estimates of the coefficients of the model's explanatory variables other than RRATIO. The estimate of the coefficient of HEAD is significantly positive. Other things equal, packers pay higher prices for spot market cattle sold in larger lots; perhaps because the purchase of a few large lots reduces transactions costs relative to the alternative of buying numerous small lots. The effect is relatively small, however. Average lot size in the sample was 190 head with a standard deviation of 127 head. The coefficient estimate predicts that an increase in lot size by one sample standard deviation would increase the price of cattle by about $\$ 0.04 /$ cwt.

The estimate of the YIELD coefficient is significantly positive. The implication of the regression result is that higher yielding cattle are paid higher live-weight prices, but lower prices on a \$/cwt. carcass basis. The sample's average value of YIELD is about $63.79 \%$. A lot of cattle yielding 1 percentage point higher than average (roughly the standard deviation of the sample's distribution of YIELD values) would receive a price $\$ 0.12 / \mathrm{cwt}$. higher than average on a live-weight basis, but $\$ 1.37 / \mathrm{cwt}$. lower than average on a carcass-weight basis.

The estimate of the coefficient of PCTPC was positive but very small and statistically insignificant. This is a surprising result, especially in view of the fact that the Choice-Select spread in boxed beef cutout values does not appear to have been unusually low during the period of analysis. Some experimentation revealed that the findings with regard to the price effects of PCTPC are very sensitive to the definition of the dependent variable (e.g., live-weight basis vs. carcass-weight basis) and the sample used.

The estimate of the coefficient of the percentage of the lot achieving yield grades 1 , 2 , or 3 is significantly positive. The value of the point estimate implies that a one sample standard deviation increase in PCTYG13 (about 6 percentage points) is rewarded with an additional $\$ 0.10 / \mathrm{cwt}$.

The average distance cattle were shipped to the plant was 60 miles with a standard deviation of 61 miles. The estimates of the coefficients of MILES and MILES2 combine to imply that a lot of cattle shipped a distance that is one standard deviation greater than the mean distance would, other things equal, be paid about $\$ 0.11 / \mathrm{cwt}$. less than a lot shipped the mean distance.

Dummy variables identifying lots of heifers and mixed lots (including steers and heifers) were included to allow for the possibility that such lots might receive a price that is discounted relative to the price paid for steers. The estimates of the coefficients of these dummy variables are difficult to interpret in isolation, however. The estimate of the coef- 
ficient of HEIFER, -9.05, when taken at face value, implies that a lot of heifers would suffer a very large price discount of nearly $\$ 9.05 /$ cwt. relative to a lot of steers, other things equal. This comparison is not particularly meaningful, however, because other things, notably average carcass weight, typically are not equal for steers and heifers.

Because ideal carcass weight differs with the sex of cattle, the variables average carcass weight and the square of the average carcass weight were included separately for lots of steers, of heifers, and of steers and heifers mixed. Estimates imply that the highest valued carcass weights were 750.2 lb., $660.7 \mathrm{lb}$., and $696.9 \mathrm{lb}$. for steer lots, heifer lots, and mixed steer and heifer lots, respectively, with, in each case, drop-offs in value for heavier and lighter carcasses. This appears to be roughly consistent with packer preferences as reflected in many marketing agreement pricing formulas. For example, one particular formula, of which we are aware, uses a base carcass characterized, in part, by the weight range 550-945 lbs., with discounts applied to both heavier and lighter carcasses.

The estimates of the coefficients of the three plant dummy variables include the effects of any not otherwise accounted for plant-specific factors including the plants' different average propensities to employ captive supply procurement methods. There were significant differences in these figures across plants, but disclosure restrictions prevent release of individual plant estimates.

The estimates of the coefficients of the purchase-day-of-the-week dummy variables ranged in absolute value from less than $\$ 0.01 / \mathrm{cwt}$. to about $\$ 0.04 / \mathrm{cwt}$., but none achieved statistical significance at conventional levels. Controlling for the other factors represented in the regression equation, there appear to be no significant differences in prices paid across days of the week.

Finally, the regression equation also included a set of purchase week dummy variables for 60 of 61 of the weeks represented in the sample. The estimates (not reported in Table 2) of the coefficients of these variables ranged in magnitude from $-\$ 0.36 / \mathrm{cwt}$. to $+\$ 0.57$ / cwt., with about $40 \%$ achieving statistical significance at the $5 \%$ level.

\section{Acknowledgments}

This article is an excerpt of a larger research report, "Econometric Analysis of Fed Cattle Procurement in the Texas Panhandle," written in fulfillment of Cooperative Agreement No. 98-PPD-01, USDA, Grain Inspection, Packers and Stockyards Administration (GIPSA). The authors gratefully acknowledge financial support from GIPSA and helpful comments provided by Professors DeeVon Bailey, Alan Love, and Richard Sexton on a preliminary draft of that report. We are also grateful for the contributions of two anonymous referees. Views expressed in this article are those of the authors and do not necessarily reflect the opinions of GIPSA or USDA.

\section{References}

Azzam, A. (1998). Captive supplies, market conduct, and the open market price. American Journal of Agricultural Economics, 80, 76-83.

Elam, E. (1992). Cash forward contracting vs. hedging of fed cattle, and the impact of cash contracting on cash prices. Journal of Agricultural and Resource Economics, 17, 205-217.

Grain Inspection, Packers and Stockyards Administration. (2002). Captive supply of cattle and GIPSA's reporting of captive supply. United States Department of Agriculture. http://www.usda. gov/gipsa/pubs/captive_supply/captive.htm. 
Hayenga, M., \& O’Brien, D. (1992). Packer competition, forward contracting price impacts, and the relevant market for fed cattle. In W. Purcell (Ed.), Pricing and coordination in consolidated livestock markets: Captive supplies, market power, and IRS hedging policy. Blacksburg, VA: Virginia Tech University, Research Institute on Livestock Pricing.

Love, H.A., \& Burton, D. (1999). A strategic rationale for captive supplies. Journal of Agricultural and Resource Economics, 24, 1-18.

Schroeder, T., Jones, R., Mintert, J., \& Barkley, A. (1993). The impact of forward contracting on fed cattle transaction prices. Review of Agricultural Economics, 15, 325-337.

Schroeter, J. (1988). Estimating the degree of market power in the beef packing industry. Review of Economics and Statistics, 70, 158-162.

Schroeter, J., \& Azzam, A. (1999). Econometric analysis of fed cattle procurement in the Texas panhandle. Report submitted in fulfillment of Cooperative Agreement No. 98-PPD-01, USDA; Grain Inspection, Packers and Stockyards Administration. http://www.usda.gov/gipsa/programspsp/txpeer/reportindex.htm.

Schroeter, J., \& Azzam, A. (2002). Captive supplies and cash market prices for fed cattle: Do delivery timing incentives explain the short-run relationship? Unpublished manuscript, Department of Economics, Iowa State University.

Ward, C., \& Schroeder, T. (1997). Understanding livestock-meat industry pricing issues. OSU Extension Facts, WF-551. Oklahoma Cooperative Extension Service. Division of Agricultural Sciences and Natural Resources. http://agweb.okstate.edu/pearl/agecon/marketing/wf-551.pdf.

Ward, C., Koontz, S., \& Schroeder, T. (1996). Short-run captive supply relationships with fed cattle transaction prices. In C. Ward, T. Schroeder, A. Barkley, \&S. Koontz (Eds.), Role of captive supplies in beef packing. USDA GIPSA-RR 96-3.

Ward, C., Koontz, S., \& Schroeder, T. (1998). Impacts from captive supplies on fed cattle transactions. Journal of Agricultural and Resource Economics, 23, 494-514.

Ward, C., Koontz, S., Dowty, T., Trapp, J., \& Peel, D. (1999). Marketing agreement impacts in an Experimental market for fed cattle. American Journal of Agricultural Economics, 81, 347-358.

Zhang, M., \& Sexton, R. (2000). Captive supplies and the cash market price: A spatial markets approach. Journal of Agricultural and Resource Economics, 25, 88-108.

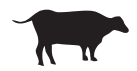

John R. Schroeter is Associate Professor, Department of Economics, Iowa State University. He received his Ph.D. from the University of Minnesota-Twin Cities in 1981. The majority of his research is in the area of empirical industrial organization.

Azzeddine Azzam is Professor and Director of the Center of Agricultural and Food Industrial Organization, Department of Agricultural Economics, University of NebraskaLincoln. He received his Ph.D. from the University of Nebraska-Lincoln in 1985. His research interest is in empirical industrial organization with a focus on livestock markets. 